\title{
Meningioma in untreated congenital adrenal hyperplasia: a relationship?
}

\author{
Annemieke C. Heijboer · J. Coen Netelenbos • \\ Marinus A. Blankenstein
}

Received: 13 August 2008/Accepted: 17 November 2008/Published online: 28 November 2008

(C) Springer Science+Business Media, LLC. 2008

\begin{abstract}
Steroid hormones have been implicated in the growth and/or development of meningiomas. A 46, XX male with untreated congenital adrenal hyperplasia who developed meningiomas is presented here. The meningiomas only expressed progesterone receptors, as most meningiomas do. The high 17-hydroxyprogesterone levels, resulting from his disease, could have played a role in the development and growth of his meningiomas.
\end{abstract}

Keywords Progesterone - Case report .

Steroid hormones · Estrogen receptors .

Progesterone receptors

\section{Introduction}

Steroid hormones are suggested to play a role in growth and/or development of meningiomas. This suggestion is based on the higher incidence of meningiomas in women compared to men [1-3], a positive association of meningiomas and breast cancer [4], a positive association between hormone replacement therapy and meningiomas [5] and accelerated tumor growth during pregnancy [6].

In this report, we present a case with untreated congenital adrenal hyperplasia who develops meningiomas.

A. C. Heijboer $(\square) \cdot$ M. A. Blankenstein

Department of Clinical Chemistry, VU University Medical

Center, Amsterdam, HV 1081, The Netherlands

e-mail: a.heijboer@vumc.nl

J. C. Netelenbos

Department of Endocrinology, VU University Medical Center,

Amsterdam, The Netherlands

\section{Case report}

A 47-year-old man with congenital adrenal hyperplasia (21-hydroxylase deficiency) presented to our hospital because of stone formation and a request for endocrinological evaluation because of feeling unwell. A male fenotype in spite of a female genotype (46, XX) was due to the 21-hydroxylase deficiency. In the past he had been treated with cortisone. However, since his puberty he stopped with the treatment because of decreasing masculinisation. He was 'salt hungry' and needed a high salt and fluid intake to keep on going. At the moment of presentation he was seen by a plastic surgeon only, who had performed many operations on his urethra. In the past he had phallus plastics, hysterectomy and placement of testicle prostheses.

On physical examination, he was $150 \mathrm{~cm}$ tall, weighed $70 \mathrm{~kg}$ and had a blood pressure of $150 / 80 \mathrm{mmHg}$. He had a striking appearance, a typical face with protruding of the right eye. His skull was in the middle longitudinally elevated (see Fig. 1). He did not have complaints about vision disturbances. A MRI of the head was obtained because of the protrusion of the eye (see Fig. 2). This revealed huge lesions, mostly extra axial, right frontal/temporal and also in the right orbita and in the intra-orbital fossa on the right site. The images were most fitting the diagnosis of two meningiomas connected with each other via tumorous changed dura. The skull appeared elevated and thickened.

Regarding the stone formation, there was no relation with urolithiasis. More likely, this phenomenon was caused by infections due to the multiple urethra operations.

Hormone measurements revealed a low plasma cortisol: $105 \mathrm{nmol} / \mathrm{l}$ (ref 250-600 nmol/l), elevated ACTH: $69 \mathrm{pmol} / \mathrm{l}$ (2-12 pmol/l), strongly elevated 17-hydroxyprogesterone: $552 \mathrm{nmol} / \mathrm{l}(0.3-4.4 \mathrm{nmol} / \mathrm{l})$. His testosterone 


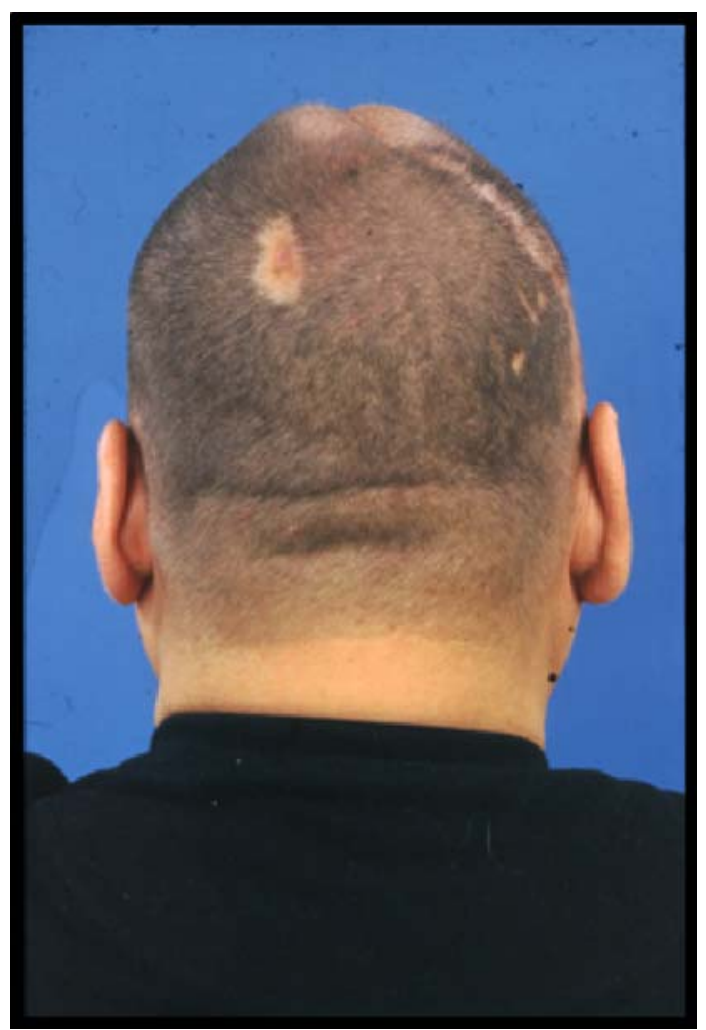

Fig. 1 The skull of the patient was elevated in the middle
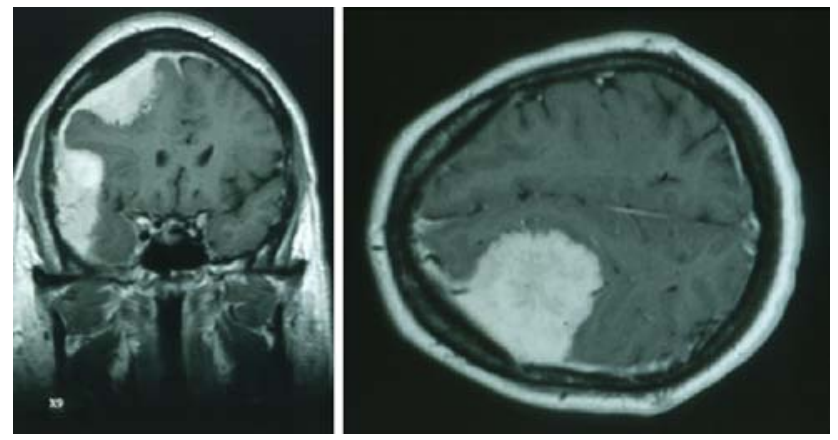

Fig. 2 Images of the meningiomas

of $15 \mathrm{nmol} / \mathrm{l}$ was normal for a man $(>8 \mathrm{nmol} / \mathrm{l})$ but too high for women $(<2.5 \mathrm{nmol} / \mathrm{l})$. Plasma estradiol was $91 \mathrm{pmol} / \mathrm{l}$ and LH and FSH were 1.5 and $8 \mathrm{U} / 1$, respectively (both within their reference range).

The patient received treatment with dexamethasone and underwent surgery, to resect as much as possible of the tumor. At operation, the tumors indeed proved to be meningiomas. At varying locations the cortex and pia were invaded by the meningiomas. Therefore, and also due to the high degree of blood loss and the protracted operation, the meningiomas could only be partial resected. The meningiomas, without malignant signs, were positive for progesterone receptor, by histochemistry, however, estrogen and androgen receptors were not detectable.
Postoperatively there was a transient hemi paresis, but otherwise good recovery. Patient refused a second operation, but got radiation therapy afterwards. His sight was not impaired. However, a few months after the operation he got some epileptic insults, for which he needed treatment. His hormonal therapy after the operation was dexamethasone, fludrocortisone and testosteronundeconaat. With this he reached an acceptable situation. 17-Hydroxyprogesterone levels decreased to $20-40 \mathrm{nmol} / \mathrm{l}$.

\section{Discussion}

This report is the second case report on 21-hydroxylase deficiency $(\mathrm{CAH})$ and meningioma in a $46, \mathrm{XX}$ male [7].

Human meningioma differ from the classical sex steroid target tissue, like the breast or uterus, in their steroid receptor expression. These meningiomas have an abundant expression of progesterone receptor (PR), whereas they essentially lack estrogen receptors (ER) [8]. In the classical sex steroid target tissue, expression of PR is regulated by estrogens via the ER. As meningioma mainly express PR, it has been hypothesised that progesterone directly affects the growth and/or development of this tumor. For instance, during the luteal phase of the menstrual cycle, a period of relative progesterone excess, increased growth of meningioma can be observed (cyclic vision problems) [9]. Another argument for the involvement of progestins in the development or growth of meningiomas is the higher incidence of meningiomas in women with lymphangioleiomyomatosis (LAM), a lung disease that is often treated with progesterone [10]. Direct evidence for such a role of progesterone in the pathogenesis of meningioma is still lacking.

In the meningiomas of this patient, as expected, PR were found, but ER and androgen receptors were not present. It is tempting to speculate that in the prolonged period in which this patient was untreated for his $\mathrm{CAH}$, progesterone levels were elevated in association with the high 17hydroxyprogesterone and that the elevated progesterone and/or 17-hydroxyprogesterone is causally related to the development of the meningiomas and/or its accelerated growth in this patient.

\section{References}

1. Nakasu S, Hirano A, Shimura T, Llena JF (1987) Incidental meningiomas in autopsy study. Surg Neurol 27:319-322. doi: 10.1016/0090-3019(87)90005-X

2. Kepes JJ (2008) Meningiomas: biology, pathology and differential diagnosis. Masson Publishing, U.S. New York, pp 17-19

3. Christensen HC, Kosteljanetz M, Johansen C (2003) Incidences of gliomas and meningiomas in Denmark, 1943-1997. Neurosurgery 52:1327-1333. doi:10.1227/01.NEU.0000064802.46759.53 
4. Kubo M, Fukutomi T, kashi-Tanaka S, Hasegawa T (2001) Association of breast cancer with meningioma: report of a case and review of the literature. Jpn J Clin Oncol 31:510-513. doi: 10.1093/jjco/hye109

5. Blitshteyn S, Crook JE, Jaeckle KA (2008) Is there an association between meningioma and hormone replacement therapy? J Clin Oncol 26:279-282. doi:10.1200/JCO.2007.14.2133

6. Roelvink NC, Kamphorst W, van Alphen HA, Rao BR (1987) Pregnancy-related primary brain and spinal tumors. Arch Neurol 44:209-215

7. Strumph PS, Stechison MT, Lee PA (1995) Meningioma in congenital adrenal hyperplasia. Endocr Pract 1:161-162
8. Blankenstein MA, Verheijen FM, Jacobs JM, Donker TH, van Duijnhoven MW, Thijssen JH (2000) Occurrence, regulation, and significance of progesterone receptors in human meningioma. Steroids 65:795-800. doi:10.1016/S0039-128X(00)00193-8

9. Bickerstaff ER, Small JM, Guest IA (1958) The relapsing course of certain meningiomas in relation to pregnancy and menstruation. J Neurol Neurosurg Psychiatry 21:89-91

10. Moss J, DeCastro R, Patronas NJ, Taveira-DaSilva A (2001) Meningiomas in lymphangioleiomyomatosis. JAMA 286:18791881. doi:10.1001/jama.286.15.1879 